\title{
Physiological plausibility and boundary conditions of theories of risk sensitivity
}

\author{
Davide Marchiori ${ }^{1 *}$ and Shira Elqayam ${ }^{2}$ \\ 1 Department of Economics, National Chengchi University, Taipei, Taiwan \\ 2 Department of Psychology, Shira Elqayam, De Montfort University, Leicester, UK \\ *Correspondence: davide@nccu.edu.tw
}

\section{A commentary on}

To take risk is to face loss: a tonic pupillometry study

by Yechiam, E., and Telpaz, A. (2011). Front. Psychol.2:344. doi: 10.3389/fpsyg.2011.00344

The contribution by Yechiam and Telpaz (Y\&T) published in Frontiers in Cognitive Science places it in a corpus of literature which bridges at least three different disciplines, i.e., psychology, economics, and neuroscience. The goal of this line of research is to explore the neurological and physiological underpinnings of one of the central topics in judgment and decision-making (JDM) research - choice behavior in decisions from experience. Y\&T successfully contributes to this goal by demonstrating a novel effect that losses increase experimental participants' arousal as measured by pupil dilatation, which in turn positively correlates with a risk aversion behavior. They hypothesize that participants' attention is increased in decision problems involving losses, which trigger an innate prudent behavior in situations entailing danger and/or hazard. Interestingly, Y\&T find that the nature of attention is not selective, i.e., when losses are present, participants are shown to devote more attention to the task as a whole rather than to the single negative outcomes, in contrast to Prospect Theory's loss aversion.

Y\&T's contribution can be highlighted in the context of research on the neural mechanism underlying loss aversion (see, for example, Breiter et al., 2001; Tom et al., 2007). These studies suggest that behavioral loss aversion in decisions from description reflects an asymmetric response to gain and losses in the neural system encoding for reward values (the ventromedial prefrontal cortex, orbitofrontal cortex, and ventral striatum). What makes Y\&T's contribution particularly noteworthy is their mediating attentional hypothesis, which links physi- ological mechanisms to the psychological processes involved in experience-based decisions.

One of the possible future developments from Y\&T's work is that of drawing on their attentional hypothesis to explain dependence of risk aversion on the payoff level, as observed in the Experimental Economics literature (Harrison et al., 2005; Holt and Laury, 2005). Specifically, it has been observed that participants' degree of risk aversion increases significantly as actual positive payoffs are scaled up, and that this effect is negligible when payoffs are hypothetical. These findings provide an opportunity to widen the scope of the attentional hypothesis. Specifically, payoffs corresponding to large cash amounts might have the analogous effects of losses of increasing arousal and of triggering a higher level of risk aversion; whereas hypothetical payoffs might result in a substantial inhibition of attention. Therefore, the motivation implied by real stakes can be interpreted as one of the possible boundary conditions (see below) for Y\&T's attentional hypothesis, giving rise to a question of the relative weight of attention and motivation in shaping risk attitudes.

Y\&T's report can also be contextualized within the wide literature on individual differences in reasoning, judgment and decision making (e.g., Stanovich and West, 2000) and their implications to the rationality debate. The prototypical finding in that literature is the correlation between cognitive ability and normative responding, with a strong emphasis on normative evaluation of rationality. This so-called "normativist" approach has recently been subject to criticism (Elqayam and Evans, 2011) as unhelpful in developing a psychological theory of human rationality. It is therefore noteworthy that Y\&T take their individual differences work in a completely different direction, with what seems to be a purely 'descriptivist' approach, with no nor- mativist connotations. As one reviewer of this manuscript put it, any behavior in this setting could be justified as 'rational'. The behavioral patterns described vary qualitatively rather than quantitatively. This is typical of descriptivist approaches to cognitive variability higher mental processing (Evans and Elqayam, 2011). Given the dearth of such focus in higher mental processing, this is a welcome development.

Lastly, a potentially significant issue here is the implications to risk aversion as originally portrayed in prospect theory (Kahneman and Tversky, 1979). One could argue that Y\&T contribute to defining boundary conditions for Prospect Theory, by proposing an alternative explanation for specific settings in which Prospect Theory is not supported by empirical evidence ${ }^{1}$. Indeed, as a unified theory of risk aversion is not yet at hand, knowing the range of application of each of the existing theories is crucial.

One reason that Y\&T in particular, and decisions from experience in general, can define boundary conditions, is their focus on the processing level of analysis. Marr (1982) famously distinguished between three levels of analysis regarding any information processing system: The computational level, which portrays the function computed by the system (e.g., arithmetic is a pocket calculator's function); the algorithmic level, which has to do with processes (e.g., the calculator's software); and the implementational level, which explores the physical underpinnings of the system - its hardware/wetware characterization (e.g., the calculator's

${ }^{1}$ Note that Prospect Theory cannot explain the typical behavioral patterns found in decisions from experience studies (see, for example, Barron and Erev, 2003 , and Erev and Haruvy, 2010), unless one assumes parameter values that imply no loss aversion, linear value function (at least with low stakes), and underweighting of rare events. We are grateful to an anonymous reviewer for pointing this out. 
chip). Viewed in these terms, we see prospect theory as portraying behavior mainly on the computational (i.e., functional) level of analysis; or, as some authors put it - an "axiomatic" system (see Wakker, 2010). In contrast, Y\&T explore the attentional processes (algorithmic level), and their physiological underpinnings (implementational level). As Marr commented, levels of analysis interact, with different processes sometimes computing different functions, as is the case here. Research questions about processing and physiology are much rarer in judgment and decision making research than computational level questions (although see, e.g., Breiter et al., 2001; Tom et al., 2007), and studies that combine several levels of analysis, as Y\&T have done, are even rarer. This makes Y\&T's contribution of particular interest to scholars of human thinking and decision making.

\section{ACKNOWLEDGMENTS}

We are grateful to Izhak Aharon and an anonymous reviewer for helpful comments on a previous version of the manuscript. This commentary also much benefited from discussions of the first author at the ErasmusTechnion Workshop on Decisions and Predictions (January 2012, Ein Bokek, Israel).

\section{REFERENCES}

Barron, G., and Erev, I. (2003). Small feedback-based decisions and their limited correspondence to description-based decisions. J. Behav. Decis. Mak. 16, 215-233.

Breiter, H. C., Aharon, I., Kahneman, D., Dale, A., and Shizgal, P. (2001). Functional imaging of neural responses to expectancy and experience of monetary gains and losses. Neuron 30, 619-639.

Elqayam, S., and Evans, J. S. (2011). Subtracting 'ought' from 'is': descriptivism versus normativism in the study of human thinking. Behav. Brain Sci. 34, 233-248.

Erev, I., and Haruvy, E. (in press). "Learning and the economics of small decisions," in The Handbook of Experimental Economics, Vol. 2, eds J. H. Kagel and A. E. Roth (Princeton, NJ: Princeton University Press).

Evans, J. St. B. T., and Elqayam, S. (2011). Towards a descriptivist psychology of reasoning and decision making. Behav. Brain Sci. 34, 275-290.

Harrison, G. W., Johnson, E., McInnes, M. M., and Rutström, E. E. (2005). Risk aversion and incentive effects: comment. Am. Econ. Rev. 95, 900-904.

Holt, C. A., and Laury, S. K. (2005). Risk aversion and incentive effects: new data without order effects. Am. Econ. Rev. 95, 902-904.
Kahneman, D., and Tversky, A. (1979). Prospect theory: an analysis of decision under risk. Econometrica 47, 263-291.

Marr, D. (1982). Vision: A Computational Investigation into the Human Representation and Processing of Visual Information. San Francisco: Freeman.

Stanovich, K. E., and West, R. F. (2000). Individual differences in reasoning: implications for the rationality debate. Behav. Brain Sci. 23, 645-726.

Tom, S. M., Craig, R. F., Trepel, C., and Poldrack, R. A. (2007). The neural basis of loss aversion in decision making under risk. Science 315, 515-518.

Wakker, P. P. (2010). Prospect Theory for Risk and Ambiguity. Cambridge: Cambridge University Press.

Yechiam, E., and Telpaz, A. (2011). To take risk is to face loss: a tonic pupillometry study. Front. Psychol. 2:344. doi: 10.3389/fpsyg.2011.00344

Received: 06 December 2011; accepted: 30 January 2012; published online: 24 February 2012.

Citation: Marchiori D and Elqayam S (2012) Physiological plausibility and boundary conditions of theories of risk sensitivity. Front. Psychology 3:33. doi: 10.3389/ fpsyg.2012.00033

This article was submitted to Frontiers in Cognitive Science, a specialty of Frontiers in Psychology.

Copyright $(2012$ Marchioriand Elqayam. This is an openaccess article distributed under the terms of the Creative Commons Attribution Non Commercial License, which permits non-commercial use, distribution, and reproduction in other forums, provided the original authors and source are credited. 